\title{
Echocardiographic Profile of Patients with Cardiomyopathy
}

\author{
Jeevan Khanal,, ${ }^{\mathrm{a}, \mathrm{c}}$ Tilchan Pandey, ${ }^{\mathrm{b}, \mathrm{c}}$ Krishna Godar,c
}

\begin{abstract}
:
Introduction: Cardiomyopathies represent a heterogeneous group of diseases that often lead to progressive heart failure with significant morbidity and mortality. Exact epidemiological data on cardiomyopathy in Nepal are lacking. This study was done to observe the demographic and echocardiographic profile of patients with cardiomyopathy attending a medical college teaching hospital. Methods: Trans-thoracic two-dimensional echocardiographic study was performed by first author on all patients with cardiomyopathy over a period of six months. Patients' demographic and echocardiographic data were collected and analyzed using SPSS version 20 software. Student t-test and Chisquare test were applied where appropriate. Results: A total of 60 patients were studied from October 2017 to March 2018. Mean age of all participants was 56.38 years $(\mathrm{SD}=13.86)$. Mean age of males was significantly higher than that of females $(60.96 \mathrm{yrs}, \mathrm{SD}=13.61$ versus $51.62 \mathrm{yrs}, \mathrm{SD}=13.47)$ in dilated cardiomyopathy subgroup $(\mathrm{p}<0.05)$. Of all patients, $32(53.33 \%)$ had dilated cardiomyopathy (idiopathic) and $13(21.66 \%)$ had ischemic cardiomyopathy. Conclusion: Our study highlighted significant burden of dilated cardiomyopathy. Dilated cardiomyopathy appeared in females at earlier age compared to males. Potentially reversible cardiomyopathies like alcoholic and peripartum cardiomyopathies were also present which have a probability of cure if treated properly.
\end{abstract}

Keywords: alcoholic cardiomyopathy, dilated cardiomyopathy, echocardiography, ischemic cardiomyopathy

Submitted: 23 March 2018

Accepted: 20 June 2018

Published: 12 July 2018

a - Consultant Cardiologist

b - Lecturer, Department of Medicine

c - Lumbini Medical College Teaching Hospital, Palpa, Nepal

Corresponding Author:

Jeevan Khanal

e-mail: postatjk@gmail.com

ORCID: https://orcid.org/0000-0001-7845-5898

How to cite this article:

Khanal J, Pandey T, Godar K. Echocardiographic profile of patients with cardiomyopathy. Journal of Lumbini Medical College. 2018;6(2):x pages. DOI: 10.22502/jlmc.v6i2.255. Epub: 2018 July 12.

\section{INTRODUCTION:}

Cardiomyopathy is a heterogeneous group of myocardial disorders associated with mechanical and/or electrical dysfunction that causes abnormal myocardial performance.[1] Cardiomyopathies either are confined to the heart or are part of systemic disease conditions often leading to progressive heart failure.[2] Within this broad definition, cardiomyopathies usually are associated with failure ofmyocardialperformance, whichmay be mechanical or electrical prone to life-threatening arrhythmias. [3] The worldwide prevalence and incidence rate of heart failure related to cardiomyopathies are approaching epidemic proportion.[4] The primary cardiomyopathy group have dilated, restrictive and hypertrophic phenotypes. The secondary cardiomyopathies are those associated with known cardiac or systemic processes. These are referred to as specific cardiomyopathies named for the disease process with which they are associated.[5] Dilated Cardiomyopathy (DCM) is considered to be an important cause of heart failure and accounts for up to $25 \%$ of all cases of congestive heart failure (CHF). [6] Out of all these, DCM is the most common form 
comprising over $90 \%$ of all cases causing sudden cardiac death.[7] The Framingham study has also reported $10 \%$ annual mortality rate for subjects having CHF.[8]

Exact epidemiological data on cardiomyopathy in Nepal are lacking. Because of the high prevalence of chronic heart failure in the country and the increasing use of echocardiography, the incidence of cardiomyopathy is increasing. The present study was undertaken to analyze etiological and echocardiographic findings in patients with cardiomyopathy attending a medical college teaching hospital.

\section{METHODS:}

This was an observational study conducted over a period of six months (July 2017 to December 2017) at Lumbini Medical College Teaching Hospital (LMCTH), Palpa. Ethical clearance for the study was taken from Institutional Review Committee of the institute.

\section{Inclusion criteria:}

- Patients with cardiomyopathy

- $\quad$ Aged more than 15 years

- Undergoing echocardiogram

\section{Exclusion criteria:}

- Not consenting to the study

Admitted patients or those visiting the Cardiology Unit of Outpatient wing of Department of Internal Medicine were studied.

Proforma included demographic profile, clinical parameters, laboratory investigations, and echocardiographic findings. Transthoracic twodimensional echocardiographic study was performed in accordance with the standard guidelines.

\section{Echocardiography techinque:}

All patients were evaluated using M-mode and two-dimensional transthoracic echocardiography and color flow doppler examination using Siemens ACUSON. The guidelines of American Society of Echocardiography were followed in obtaining measurements.[9]

Systolic dysfunction was characterized by reduced ejection fraction (EF) $<55 \%$. Diastolic dysfunction was calculated by measuring $\mathrm{E}$ and A velocity across trans-mitral inflow velocity and tissue doppler imaging. Diastolic dysfunction was characterized by (a) reduced early diastolic filling, (b) prolonged isovolumetric relaxation time, (c) increased atrial filling, (d) increased pre-ejection time and (e) reduced left ventricular ejection time. Left ventricular hypertrophy (LVH) was defined by left ventricular posterior wall (LVPW) $>10 \mathrm{~mm}$ and inter-ventricular septum (IVS) $>10 \mathrm{~mm}$ by M-mode. DCM was labeled if enlarged left ventricle with decreased systolic function was present as measured byleft ventricular ejection fraction(LVEF); excluding ischemic, valvular, hypertensive or congenital causes. Ischemic cardiomyopathy was labeled on the basis of documented history of previous myocardial infarction or acute coronary syndrome. HCM was defined by a thickened but nondilated left ventricle in the absence of another cardiac or systemic condition such as aortic valve stenosis, systemic hypertension. HOCM was defined by thickened and nondilated left ventricle in the absence of other causes, such as hypertension or valve disease, with LVOT obstructive gradient more than $30 \mathrm{~mm}$ of $\mathrm{Hg}$ at rest. Peripartum cardiomyopathy was characterized by features of DCM was present with onset in the last month of pregnancy or in the first five months after delivery. Alcohol associated cardiomyopathy was labeled if features of DCM was present in patient with chronic alcoholism potentially reversible with abstinence from alcohol use.

\section{Statistical analysis:}

Statistical analysis of data was done using Statistical Package for Social Sciences (SPSSTM) version 20 software. All results were presented as frequency and percentages, and mean and Standard Deviation (SD). Two means were compared with unpaired t-test. Categorical variables were analyzed with Chi-square or Fisher exact test. A p value of less than 0.05 was considered significant.

\section{RESULTS:}

A total of 60 patients with diagnosis of cardiomyopathy were included in the study. Mean age was 56.38 years $(\mathrm{SD}=13.86)$. Out of 60 patients, 34 (56.66\%) were males with mean age of 61.11 years $(\mathrm{SD}=11.36)$ and $26(43.33 \%)$ were females with mean age of 52.79 years $(\mathrm{SD}=16.28)$. There was significant statistical difference between genders in DCM subgroup ( $p<0.05)$. Baseline characteristics of the patients is shown in Table 1. 
Table 1: Baseline characteristics of patients with cardiomyopathy

\begin{tabular}{|c|c|c|c|c|}
\hline \multirow[t]{2}{*}{ Variables } & \multirow[t]{2}{*}{ n (\%) } & \multicolumn{2}{|c|}{$\begin{array}{l}\text { Mean age in } \\
\text { years (SD) }\end{array}$} & \multirow[t]{2}{*}{$P$} \\
\hline & & Male & Female & \\
\hline Total population & $\begin{array}{c}60 \\
(100 \%)\end{array}$ & $\begin{array}{c}61.11 \\
(11.36)\end{array}$ & $\begin{array}{c}52.79 \\
(16.28)\end{array}$ & \\
\hline $\begin{array}{l}\text { Dilated } \\
\text { cardiomyopathy }\end{array}$ & $\begin{array}{c}32 \\
(53.33 \%)\end{array}$ & $\begin{array}{c}60.96 \\
(13.61)\end{array}$ & $\begin{array}{c}51.62 \\
(13.47)\end{array}$ & $<0.05$ \\
\hline $\begin{array}{l}\text { Ischemic } \\
\text { cardiomyopathy }\end{array}$ & $\begin{array}{c}13 \\
(21.66 \%)\end{array}$ & $\begin{array}{c}67.91 \\
(12.89)\end{array}$ & $\begin{array}{c}66.25 \\
(11.46)\end{array}$ & 0.6 \\
\hline $\begin{array}{l}\text { Alcoholic } \\
\text { cardiomyopathy }\end{array}$ & $9(15 \%)$ & $\begin{array}{l}52.32 \\
(5.76)\end{array}$ & N/A & \\
\hline $\begin{array}{l}\text { Hypertrophic } \\
\text { cardiomyopathy }\end{array}$ & $2(3.33 \%)$ & $\begin{array}{l}49.33 \\
(8.13)\end{array}$ & N/A & \\
\hline $\begin{array}{l}\text { Hypertrophic } \\
\text { obstructive } \\
\text { cardiomyopathy }\end{array}$ & $1(1.66 \%)$ & 44 & N/A & \\
\hline $\begin{array}{l}\text { Peripartum } \\
\text { cardiomyopathy }\end{array}$ & $3(5.0 \%)$ & $\begin{array}{l}34.15 \\
(6.24)\end{array}$ & N/A & \\
\hline
\end{tabular}

Out of the total 60 patients with cardiomyopathy studied; 32 (53.33\%) had idiopathic, $13(21.66 \%)$ had ischemic cardiomyopathy. A total of $9(15.0 \%)$ patients had alcoholic cardiomyopathy, $3(5.0 \%)$ had peripartum cardiomyopathy (PPCM), $2(3.33 \%)$ had HCM, 1 (1.66\%) had HOCM. In this study DCM was the most common cardiomyopathy (Table 1).

Out of 32 patients diagnosed with DCM, 19 (59.37\%) were males and 9 (40.62\%) were females. Out of 13 patients diagnosed with ischemic cardiomyopathy, $8(61.53 \%)$ were males and 5 (38.46\%) were females. Out of 3 patients diagnosed with HCM, all (100\%) were males. There were 3 female patients who were diagnosed with PPCM. All the 9 patient diagnosed with cardiomyopathy secondary to chronic alcohol consumption were males.

Out of 32 patients with DCM, $20(62.5 \%)$ had diastolic dysfunction (DD) as well, by echo criteria. Total of $13(100 \%)$ of ischemic cardiomyopathy, $100 \%$ of HCM and HOCM, $11.11 \%$ of alcoholic cardiomyopathy patients had diastolic dysfunction. None of the patients with PPCM had diastolic dysfunction.

Total three (9.37\%) out of 32 patients with DCM had left ventricular (LV) clot and 1 (3.12\%) patient had echo-contrast in LA/LV. The presence of LV clot in patients with DCM was significant statistically $(\mathrm{p}<0.05)$. Out of 32 patients with DCM, $26(81.25 \%)$ patients had mitral regurgitation and 21 (65.62\%) patients had tricuspid regurgitation ( $\mathrm{p}<$ 0.05) (Table 2).

\section{DISCUSSION:}

We compared the results of this study with various other studies. The DCM is frequently caused by coronary artery disease (CAD) and hypertension. [10] DCM most commonly occurs in middle age. [11] In our study, mean age of patients with DCM was $60.96 \pm 61$ years in male and $51.62 \pm 13.47$ years in female. In another study by Ahmad S et al,[12] the mean age was $51.39 \pm 17.7$ years.

In a study by Pacheco OE et al,[13] ischemic cardiomyopathy was identified as the most common cause of DCM, representing $37 \%$ of the patient and $22 \%$ had idiopathic etiology. In contrast to it, idiopathic was most common (53.33\%) and next to it was ischemic cardiomyopathy (21.66\%). The incidence rate of six per hundred thousand person per year was reported in ischemic cardiomyopathy by MB Cod et al.[14]

Of the 60 patients, $3(5 \%)$ had peripartum cardiomyopathy. The mean age was $34.15 \pm 6.24$ years in our study. PPMC has been reported mostly in women older 30 years.[15]

The incidence of peripartum cardiomyopathy

Table 2: Echocardiographic findings in patients with cardiomyopathy

\begin{tabular}{lcccccc}
\hline Types of cardiomyopathy (n) & $\begin{array}{c}\text { LVEF } \\
( \pm \text { SD)\% }\end{array}$ & DD (\%) & $\begin{array}{c}\text { Clot } \\
(\%)\end{array}$ & $\begin{array}{c}\text { Echo- } \\
\text { contrast (\%) }\end{array}$ & MR (\%) & TR (\%) \\
\hline Dilated cardiomyopathy (32) & $28( \pm 7.7)$ & $20(62.5)$ & $3(9.37) *$ & $1(3.12)$ & $26(81.25)$ & $21(65.62) *$ \\
Ischemic cardiomyopathy (13) & $36( \pm 9.5)$ & $13(100)$ & $0(0)$ & $0(0)$ & $8(61.53)$ & $3(23.07)$ \\
Alcoholic cardiomyopathy (9) & $39( \pm 8.2)$ & $1(11.11)$ & $0(0)$ & $0(0)$ & $2(22.22)$ & $4(44.44)$ \\
Hypertrophic cardiomyopathy(2) & $66( \pm 12.5)$ & $2(100)$ & $0(0)$ & $0(0)$ & $0(0)$ & $0(0)$ \\
Hypertrophic obstructive Cardiomyopathy (1) & $71( \pm 11.3)$ & $1(100)$ & $0(0)$ & $0(0)$ & $1(100)$ & $0(0)$ \\
Post-partum cardiomyopathy (3) & $34( \pm 8.7)$ & $0(0)$ & $0(0)$ & $0(0)$ & $0(0)$ & $1(33.33)$ \\
\hline
\end{tabular}

${ }^{*}$ p-value $<0.05$ 
is reported to be 1 in 4000 pregnancies.[16] In a study in Pakistan, peripartum cardiomyopathy was reported to be 1 in 837 deliveries.[17] In our institution, $3(5 \%)$ patients with cardiomyopathy, out of 60 study population, were admitted due to decompensated left heart failure. None of the patients with PPCM had diastolic dysfunction, LV clot and valvular regurgitation.

We also noticed complications of cardiomyopathies on echocardiographic study. Most common complications were intra-cardiac thrombi in $9.37 \%$, spontaneous echo-contrast in $3.12 \%$, mitral regurgitation in $81.25 \%$, tricuspid regurgitation in $65.62 \%$.

In the present study, total $3(5.0 \%)$ had HCM, 1 (1.66\%) had HOCM. 5\% HCM in our study that included the clinical cases in our hospital, seems much less compared to the study by Phadke R S et al, who reported $13.9 \%$ among the autopsy cases. [18]

Excess alcohol intake may be manifested by features of DCM. The incidence of alcoholic cardiomyopathy has been reported to be $21 \%$ to $32 \%$ of DCM.[19] It more commonly occurs in male.[20] We had $15 \%$ of DCM presenting with ACM. All patients were male in our study.

\section{CONCLUSION:}

Present study highlights significant burden of idiopathic dilated cardiomyopathy and next to it was ischemic cardiomyopathy. Dilated cardiomyopathy appeared earlier in females as compared to males $(\mathrm{p}<0.05)$. A total of $12(20 \%)$ patients had potentially reversible cardiomyopathy like peripartum and alcoholic cardiomyopathy. The presence of LV clot and tricuspid regurgitation were significantly higher $(p<0.05)$ in patients with dilated cardiomyopathy.

\section{Conflict of interest:}

None declared.

\section{Source of funds:}

No fund was available.

\section{REFERENCES:}

1. Mann DL, Zipes DP, Libby P, Bonow RO, Braunwald E. A Braunwald's heart disease -Textbook of Cardiovascular Medicine: Dilated cardiomyopathy. 10th Ed.Philadelphia: Elsivier Saunders;2015, pp.1551-62.

2. Elliott $P$, Andersson B, Arbustini E, et al: Classification of the cardiomyopathies: A position statement from the European Society of Cardiology Working Group on Myocardial and Pericardial diseases. Eur Heart J 29:270, 2008.

3. Maron BJ, Towbin JA, Thiene G, et al. Contemporary Definitions and Classification of the Cardiomyopathies. Circulation 2006;113:1807-16.

4. Go As, Mozaffarian D, Roger VL. Heart disease and stroke statistics-2013 update:A report from the American Heart Association. Circulation 127:e6, 2013

5. Rubin E. Alcohol and the heart. N Engl J Med. 1979; 301 :28-33

6. Anderson KM, Kannel WB. Prevalence of congestive heart failure in Framingham Heart study subjects. Circulation 1994;13:S107-S112

7. Cohn JN, Bristow MR, Chien KR. Report of the national heart, lung, and blood institute special emphasis panel on heart failure research. Circulation 1997;95:766-70.

8. Kalon K.L., Keaven M. Anderson, William B. Kannel, William Grossman, Daniel Levy. Survival After the Onset of Congestive Heart Failure in Framingham Heart Study Subjects. Circulation 1993;88:107-115.

9. Feigenbaum H, Armstrong WF, Rayn T. Dilated and Hypertrophic cardiomyopathy. Feigenbaum's Echocardiography, 7th Asian edition 2010 Philadelphia. Wolters Kluwer. 507-60.

10. Randy Wexler, Terry Elton, Adam Pleister, David Feldman. Cardiomyopathy: An Overview. Am Fam Physician. 2009; 79(9): 778-84.

11. Praful JD, Sachin MN.Clinical profile of patients with dilated cardiomyopathy-A study of 50 cases. Journal of Research in Medical and Dental Sciences. 2016; 4(3)

12. Ahmad S, Rabbani M, Zaheer M, Shirazi N. Clinical ECG and echocardiographic profile of patients with dilated cardiomyopathy. Indian J Cardiol. 2005;8:25-9.

13. Pacheco OE, Novoa JE, Cox RA. Dilated cardiomyopathy: a clinical review of patients evaluated at a tertiary care center in Puerto Rico. P R Health Sci J. 1995;14(4): 269-73.

14. Codd MB, Sugrue DD, Gersh BJ and Melton LJ Epidemiology of idiopathic dilated and hypertrophic cardiomyopathy. A population-based study in Olmsted County, Minnesota. 1975-1984. Circulation. 1989; 80: 564-72.

15. Hasan AH, Qureshi A, Ramejo BB, et al. Peripartum cardiomyopathy characteristics and outcome in a tertiary care hospital. JPMA. 2010: 60; 377-80.

16. Ntobeko BA Ntusi, Ambroise Wonkam, Gasnat Shaboodien, Motasim Badri, Bongani M Mayosi. Frequency and clinical genetics of familial dilated cardiomyopathy in Cape Town: Implications for the evaluation of patients with unexplained cardiomyopathy. S Afr Med J. 2011;101: 1-5.

17. Haq Nawaz, Rehan Ahmed, Nasir Ahmed, Abdul Rashid. Frequency of Echocardiographic Complications Of Dilated Cardiomyopathy At A Tertiary Care Hospital. J Ayub Med Coll Abbottabad. 2011; 23(3): 51-5.

18. Phadke R S, Vaideeswar P, Mittal B, Deshpande J. Hypertrophic cardiomyopathy: an autopsy analysis of 14 cases. J Postgrad Med. 2001; 47:165.

19. Regan TJ. Alcohol and the cardiovascular system. JAMA, 1990;264:377-381.

20. Ely M, Hardy R, Longford NT, Wadsworth MEJ Gender differences in the relationship betweenalcohol consumption and drink problems are largely accounted for by body water. Alcohol and Alcoholism.1999;34:894-902. 